\title{
Short Video - a New Approach to Language International Education
}

\author{
Si Xi \\ Ural Federal University, Ekaterinburg, China - Russia \\ 809521688@qq.com
}

\begin{abstract}
Educational opportunities of new media are investigated on the example of the TikTok social network, especially provided opportunities in the field of studying Russian as a foreign language. The attention is paid to the teaching opportunities of short videos in TikTok, and the reasons for the spread of TikTok for teaching Russian are analyzed. It is concluded that short videos allow you to concentrate attention, they have a bright emotional specter and contribute to good memorization of new vocabulary, correct intonation of pronunciation and give visual video examples of the use of new vocabulary. All this allows us to call the use of the TikTok network an effective tool in teaching foreigners Russian vocabulary and Russian speech.
\end{abstract}

Keywords: e-learning, new media, Russian as a foreign language, social network, TikTok (Douyin)

With the popularization of social networks, short video platform has become one of the most important communication channels for people to transmit and share knowledge, and is gradually involved in the field of language international education and dissemination. This thesis is confirmed by the research of such scientists as A. Mikhailova [Mikhailova, 67] and J. Teng [Teng, 90]. For the learning of Russian as a second language, short video can make rational use of fragmented time, teach one or two knowledge points that can facilitate rapid memory of learning languages, which is also a good choice for learners using short video in free time for informal learning, Short videos can make rational use of fragmented time, teach one or two knowledge points that can facilitate rapid memory of language learning, and for non-native Russian language learners, using short videos as an informal learning method is also a good choice.

This paper will take short video platform TikTok (Douyin) and Russian teaching promoting self-media in this platform as research object, to explore 
the situation, characteristics, advantages and disadvantages of international education of Russian language in this short video platform. And put forward corresponding improvement measures for IER to provide a little reference.

\section{The current state of international education of Russian language on the TikTok(Douyin)}

\subsection{Why TikTok (Douyin)?}

TikTok, which Chinese pattern named Douyin is a short video-sharing social networking service. It is used to create short music, lip-sync, dance, comedy and talent videos of 3 to 15 seconds, and short looping videos of 3 to 60 seconds.

\subsubsection{Huge user base}

The huge Mass and international distribution provide a quick way and a wider stage for the IER.

As of January 2020, TikTok has reached more than 150 countries worldwide, with more than 400 million DAU (Daily Active User). TikTok received nearly 315 million downloads from the App Store and Google Play in the first quarter of 2020, bringing its total downloads to 2 billion, while the Chinese version had 518 million users and 28.5 hours per person per month, According to Sensor Tower, a world-renowned app tracking company [Sensor, 2020].

\subsubsection{Easy to operate, low creation threshold}

No need for a lot of professional equipment and expensive costs, having a mobile phone, knowing a little shooting technology and video editing technology can successfully complete a short video.

First, TikTok (Douyin) has provided a large amount of video footage and templates which have reduced the short video creation threshold. To meet the creative's editing needs, TikTok (Douyin) has also launched an easy-to-understand, efficient editing app - Viamaker, which is close to popular usage habits and creative preferences. In Viamaker, a few simple steps can be completed similar to the special effects processing from computer side. A large number of video templates can be use. The platform also shares a variety of editing techniques for the general public to learn.

\subsubsection{Precise "recommended" algorithms}

The intelligent algorithm recommendation mechanism of TikTok(Douyin) can push precision content to the target audience.

TikTok (Douyin) pushes video content from the same creator or related topic based on big data such as audience attention, likes, comments, retweets, 
and video viewing integrity. That is, if a user likes, shares, or searches for the keyword "Russian/ Russian language," the user will be recommended for more Russian-related content based on that data.

\subsubsection{Supported creative environment}

TikTok (Douyin) actively supports the sharing and dissemination of short videos of knowledge such as cultural education, which provides a good creative environment for the self-media of Russian international education videos.

In March 2019, TikTok (Douyin) announced the launch of an international education campaign for short video languages called the "Dou Zhi Project", a full-service program for knowledge content creators: a priority open collection feature, a targeted growth program, and a system-based creative tool [Short Video and Knowledge Communication Research Report, 2019]. Further increase the support of short video accounts for language international education. The video's self-media provides a good creative environment. In order to achieve the combination. $10^{\text {th }}$ October 2019, TikTok launched the \#EduTok Program, which is a multi-phased integrated initiative with the objective of democratising learning for the Indian digital community on the platform. The goal of the \#EduTok program is to empower the TikTok users, so they create meaningful and relevant content on a variety of topics including the theme of education.

\section{Analysis of Russian international education from TikTok (Douyin)}

The author take TikTok (Douyin) Russian language education — short video content as a data source, through the creator's fan amount, short video amount, likes, video features, access to more influential self-media involving Russian international education TikTok and Douyin, the basic information is as follows*:

* The criteria are as follows: First, in line with the basic definition of Russian knowledge creators, that is, specializing in Russian promotion, language international education activities account. Such accounts can be divided into international educational accounts in typical Russian languages and accounts that occasionally promote international education in Russian languages according to the knowledge of Russian. Second, the selected creator samples have a certain influence in this field. That is, to meet the following characteristics: update frequency is not less than 7 days / time, in TikTok published the total number of works received more than 250,000, shaking sound of more than 50,000. 
(TikTok)

\begin{tabular}{|c|c|c|c|c|c|c|}
\hline Creator & 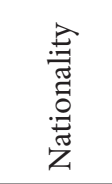 & 离 & 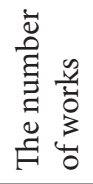 & 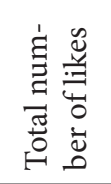 & 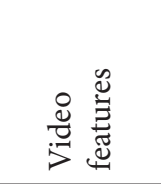 & 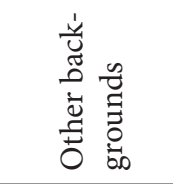 \\
\hline Lada92 & Russia. & 4391000 & 185 & $6.7 \mathrm{~m}$ & creativity & ЕГЭ \\
\hline 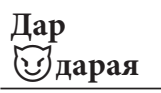 & Russia. & $285.6 \mathrm{k}$ & 231 & $66 \mathrm{~K}$ & $\begin{array}{l}\text { Cross- } \\
\text { culture }\end{array}$ & \\
\hline E-Russian & Russia. & $16.5 \mathrm{k}$ & 241 & 66.ok & Pics & $\begin{array}{c}\text { For foreign- } \\
\text { ers }\end{array}$ \\
\hline $\begin{array}{l}\text { Russian } \\
\text { lessons }\end{array}$ & Russia. & 28 & 186 & $262.2 \mathrm{~K}$ & traditional & \\
\hline $\begin{array}{l}\text { Alyssa } \\
\text { Lyssa }\end{array}$ & Russia. & $111.5 \mathrm{k}$ & 138 & $3.5 \mathrm{~m}$ & & \\
\hline
\end{tabular}

(Douyin)

\begin{tabular}{|c|c|c|c|c|c|c|}
\hline Creator & 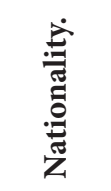 & 离 & 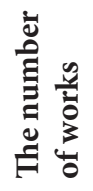 & 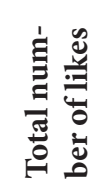 & 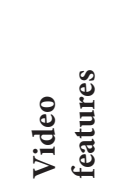 & 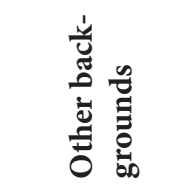 \\
\hline $\begin{array}{l}\text { Russian teacher } \\
\text { Dima }\end{array}$ & Russia. & $69,1 \mathrm{~K}$ & 623 & $537 \mathrm{~K}$ & $\begin{array}{c}\text { Role } \\
\text { playing }\end{array}$ & $\begin{array}{l}\text { Lived in Chi- } \\
\text { na for seven } \\
\text { years. }\end{array}$ \\
\hline Russian girl & & $26 \mathrm{~K}$. & & & & \\
\hline $\begin{array}{l}\text { Naja learns } \\
\text { Russian }\end{array}$ & China. & $100 \mathrm{~K}$. & 431 & $2230 \mathrm{~K}$ & & \\
\hline $\begin{array}{l}\text { Martha's Rus- } \\
\text { sian Transla- } \\
\text { tion Studio, } \\
\text { Fenhe City }\end{array}$ & $\begin{array}{l}\text { China } \\
\text { and } \\
\text { Russia. }\end{array}$ & $88 \mathrm{~K}$ & 458 & $55 \mathrm{~K}$ & & $\begin{array}{c}\text { Training } \\
\text { institutions. }\end{array}$ \\
\hline Study Russian & China. & $15 \mathrm{~K}$ & 411 & $156 \mathrm{~K}$ & & $\begin{array}{c}\text { Live } \\
\text { in Russia. }\end{array}$ \\
\hline $\begin{array}{l}\text { Katyusha, } \\
\text { Russia }\end{array}$ & Russia. & $120 \mathrm{~K}$ & $\begin{array}{l}219 \\
\text { (Cul- } \\
\text { ture) }\end{array}$ & $147 \mathrm{KK}$ & & $\begin{array}{c}\text { Study } \\
\text { at Shandong } \\
\text { University. }\end{array}$ \\
\hline
\end{tabular}


End of Table

\begin{tabular}{|c|c|c|c|c|c|c|}
\hline Creator & 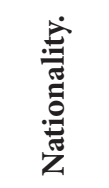 & 壱 & 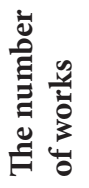 & 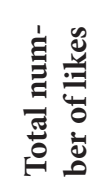 & 율 & 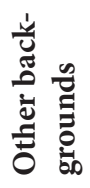 \\
\hline Eat & China. & $100 \mathrm{~K}$ & 426 & $222 \mathrm{KK}$ & $\begin{array}{c}\text { Chinese } \\
\text { transla- } \\
\text { tion. }\end{array}$ & \\
\hline $\begin{array}{l}\text { Martha's Sauce } \\
\text { (Russian) }\end{array}$ & Russia. & 29000 & 222 & $228 \mathrm{~K}$ & $\begin{array}{l}\text { Movies, } \\
\text { songs. }\end{array}$ & \\
\hline
\end{tabular}

\subsection{The type and characteristics of Russian international education} from TikTok (Douyin)

\subsubsection{Traditional teaching with rich digitized information}

The traditional "teachers, books, blackboard" - style Russian education and communication model is relatively flat, abstract, lack of expressiveness. No matter how teachers paint and teach, it is difficult to create a rich and changeable language environment. Short video can break the linear structure of language knowledge tradition and give full play to the characteristics of digital into graphic, text, sound and image. In the sample, some creators choose not to on-camera, based on the design of traditional teaching scenes, fusion of sound, subtitles, images, props, so that abstract knowledge becomes concrete, three-dimensional. This type of creator are@E-Russian @Russian lessons, and @娜佳学俄语. Most of them interpret Russian by translation, usually with the English alphabet (or Chinese Pinyin). @E-Russian presents her knowledge of Russian in both Spanish and English. Other creators use fragments of Russian acoustic films, TV dramas, musicals, and MV as learning materials for oral, listening, and sentence teaching. Generally used is the dialogue re-reading, dialogue dictation, role-playing and other forms. This original, colorful content, real language environment of the language, is very helpful to Russian learning.

\subsubsection{Life-like fun teaching}

Some creators choose to be show up and explain language knowledge face-to-face with their audience. @Lada92 brings Russian vocabulary teaching to life. In her design, the words on the cards seem to have life, not abstract language symbols, but become a symbolic thing. She wrote ВАРЕНИК on 
the dumpling to indicate the noun "meaning" of the word, placed a card with the word ВАРЕНЫИ in a boiling pan to represent the action represented by the word, and then removed and cut out the ВАРЕНЫЙ card to represent the state of its representation with the word ВАРИТЬ. Finally, cover the card with flour, gently sweep away the flour, slowly show the root and suffix of the word, and finally put together for word contrast, deepen memory. Through the scene integration, switching and a variety of teaching props, the audience step into a strong curiosity, concentration in 30 seconds, unconsciously remember the knowledge points. By using short videos, @ Lada92 hidden the word, allowing obscure knowledge points to jump out of the category of "grammar" or "vocabulary", which is both visible and distinctive, and is therefore popular with the public. The video alone has $71.7 \mathrm{~K}$ likes.

The addition of real image to the original standardization, "de-humanization" of knowledge, re-personalized, "personality", knowledge is no longer the "dead knowledge" in the book, began to live, but also close the distance between knowledge and people. @ Гараз Любовь @俄语大妞儿@俄语老 师dima@卓雅说俄语@俄罗斯喀秋莎 are of this type. @Russian@Russian with Aurora @Tata teaches Russian are new in TikTok, the number offans and the number of works is relatively less but also very promising.

\subsubsection{Integrate into life situations and compare cultural differences}

Cross-cultural communication is an important subject in the international education of Russian. In TikTok (Douyin), a large proportion of the creators who teach Russian have cross-cultural backgrounds. Cross-cultural people bring their own topics and other perspectives, covering a richer, more diverse and three-dimensional real language applications, with cross-cultural communication functions. They have warm, open, forthright characteristics, willing to show themselves in all aspects, can take the initiative to speak out and dare to express, and strive to cater to the audience's entertainment and cultural consumption psychology, the audience is usually attracted by the above characteristics, so feel fresh and interesting and give more attention and tolerance. For example, with a background in life in Russia, Ukraine, and America, @Alyssa Lyssa often imitates and compare the reactions of Russian mothers and American mothers in the same circumstance. For example, "How moms say 'good morning", "Goingto college" and "When you hurt". 
In the Douyin China, Chinese people@找国铁蛋@小笙在鹅国 who live, study in Russia, and Russians @ 青岛小菠萝@俄罗斯大卫 living in China released a series of short videos documenting their living conditions in foreign countries and sharing the similarity between Life and Culture between China and Russia. In such videos, they are more inclined to break down the misunderstandings of cultural barriers and offer advice on Russian life and communication. As user-produced content, cross-cultural self-media through the "other" perspective of two or more social cultures mirror projection, contrast the realization of different cultures of communication, collision and connection, broaden the audience's "world imagination", on the other hand, these creators through video to a certain extent to achieve the two-way dissemination and communication of different cultures.

\subsection{Problems with Russian language international education in TikTok}

(Douyin) platform

TikTok (Douyin) in a diversified communication mode, multi-modal content presentation, combined with interactive, shared socialization concept, in the form of "microlingual international education" to popularize Russian knowledge, in the dissemination of language knowledge to provide a new way encountered a new challenge at the same time.

2.2.1. Content quality is different, content in short video teaching is very fragmented, can not replace the main teaching method, if the short video as the main teaching method and means both teachers and students can feel that knowledge in short videos are too trivial and many things are fragmented, even if they are to be used. It's also time-consuming and labor-consuming to sum things up.

2.2.2. Lack of authority and leadership, discourse influence needs to be enhanced. On one hand, the audit and norms of Russian knowledge popularization in TikTok (Douyin) exists deficiencies, language knowledge dissemination platform in the content construction lack of strict control, on the other hand, the construction of knowledge circle lack of authority-driven effect, the spread of the field is relatively small, the closure of the circle led knowledge reproduction and value-added can not play a "power."

2.2.3. Audience data mining is not enough, feedback attention needs to be enhanced. The TikTok (Douyin) platform for language knowledge dissemination lacks content construction orientation and is not well targeted by reading groups. The platform pays insufficient attention to the audience's information needs and has low utilization of feedback information. 


\section{Advice on international languages education in social networks}

The Russian language studied in this paper is only an example of international language education in the TikTok/(Douyin) environment, and we can see that more and more language knowledge-sharers from different cultures in different countries are making voices through new media such as social networks. Similar problems will arise above, therefore, the author for the creators to provide the following optimization recommendations, for reference only.

3.1. Gain insight into the international education mechanism for the TikTok (Douyin) increase investment of international language education in social networks. Audience habits can be investigated, in the push of the use of guided text should be related to video content, can be refined essence, combined with hot spots and audience preferences, individual accounts should enhance their activity, the use of social media matrix to connect audiences.

3.2. Improve the external skills of "language knowledge specialty" and bridge the cognitive gap between diverse audiences. As far as possible to indicate the source of native knowledge, such as the departments, institutions or individuals responsible for that knowledge, as far as possible to elaborate the objective value of scientific and technological knowledge, rational value and its comprehensive advantages and disadvantages for social development.

3.3. Create distinctive, cultivate professional opinion leaders. In the content dimension to form characteristics, in the mode of communication and communication channels, you can try to build a new media language international education network, and even set up or hire a professional team of art, for the aesthetic of scientific communication.

3.4. Cultivate exclusive audio-visual languages to preempt international language education with personalized characteristics. Help audiences develop healthier content browsing habits, make them understand the content quality gap in the social networking platform, improve cognitive sense of "aesthetic literacy", complete, clear, high-quality video expression to pursue a unique holistic model, improve their own recognition.

3.5. Improve audience stickiness and enhance the influence of scientific communication with good "retention" effect. Increase your identity through online and offline activity.

\section{Conclusions}

Information creates value, and among the many values created by information, the value of knowledge dissemination is the especially high. On 
the TikTok (Douyin) platform, the subject of Russian teaching can no longer be confined to the state, teaching institutions, the community "art industry has specialized" creators; Any interested, relevant, and engaged international audience can participate in the construction of language connectivity. Individual learning has been transformed into mass sharing and mass participation, and the knowledge of people and people is interconnected, becoming a real human university in the mobile Internet world. TikTok (Douyin) short videos drive the production of knowledge from elite to mass, making it possible to promote the universality of knowledge, the promotion of knowledge, the sharing of knowledge and co-creation. Even more gratifying is that after the DOU Know-How Program, we can see that some other Internet platforms have also launched a variety of service knowledge dissemination initiatives, "knowledge content in the Internet industry has received unprecedented attention." However, at present, TikTok (Douyin) presents a pan-entertainment-oriented, knowledge-based ecological landscape. Pan-entertainment content is far more quantitative and quality than pan-knowledge content.

\section{References:}

1. A. Mikhaylova. Trendy sotsial'nykh setey v 2020 godu (Social media trends in 2020). Muzey. (2020). № 4. pp. 64-68.

2. Y. Teng. Format korotkikh video v prilozhenii tiktok: sekret populyarnosti i vliyaniye na podrostkov. V sbornike: Studencheskaya nauka kak resurs innovatsionnogo potentsiala razvitiya. Materialy i doklady. Otvetstvennyy redaktor L.P. Zemskova. (Short videos format in tiktok app: the secret of popularity and influence on teenagers. In the collection: Student science as a resource for innovative development potential. Materials and reports. Executive editor L. P. Zemskova). (2019). pp. 90-94.

3. T. Sensor. TikTok Crosses 2 Billion Downloads After Best Quarter For Any App Ever [EB/OL]. http://sensortower.com/blog/tiktok-downloads-2-billion (Accessed 30 April 2020).

4. Short Video and Knowledge Communication Research Report. Tsinghua University School of Journalism and Communication, China Science News Agency Joint Byte Beat Platform Responsibility Research Center (January 8, 2019). 